\title{
ANNOTATION-BASED LEARNER'S PERSONALITY MODELING IN DISTANCE LEARNING CONTEXT
}

\author{
Nizar OMHENI \\ Institute of Computer Science and Management \\ Kairouan University, Tunisia \\ Anis KALBOUSSI \\ Institute of Computer Science and Management \\ Kairouan University, Tunisia \\ Omar MAZHOUD \\ Institute of Computer Science and Management \\ Kairouan University, Tunisia \\ Ahmed Hadj KACEM \\ Faculty of Economics and Management \\ Sfax University, Tunisia
}

\begin{abstract}
Researchers in distance education are interested in observing and modeling learners' personality profiles, and adapting their learning experiences accordingly. When learners read and interact with their reading materials, they do unselfconscious activities like annotation which may be key feature of their personalities. Annotation activity requires the reader to be active, to think critically, to analyze what has been written, and to make specific annotations in the margins of the text. These traces are reflected through underlining, highlighting, scribbling comments, summarizing, asking questions, expressing confusion or ambiguity, and evaluating the content of reading. In this study, we present a new approach to build learners' personality profiles based on their annotation traces yielded during active reading sessions. To validate our approach, we invited 100 volunteers ranging in age from 22 to 50 years old. The participators were instructed to utilize our system to achieve their reading and annotation activities. We apply the paired t-test to evaluate the system's efficiency to measure user's human traits versus the scores of his personality traits measured using the Neo-IPIP inventory. The experimental results show the system performance to measure, with reasonable accuracy, the scores of learner's personality traits.
\end{abstract}

Keywords: Annotations, learner's personality traits, personality computing, learning personalization, learner modeling.

\section{INTRODUCTION}

"It's evident for anyone who has taught a course that students are not a homogeneous group. They come into courses with major individual differences among their level of knowledge about subject matter content, their intellectual and meta-cognitive skills, their beliefs and attitudes toward the topic and toward learning" (Ambrose \& Lovett, 2014, p. 7) as well as their human personality characteristics. For such reasons, some students in some classrooms might learn more than students in the same or another classroom. Thus, it's necessary to adapt teaching activities to different student characteristics. 
Personality traits are one of the student's individual characteristics which extensively interest educational experts. Several works have shown the significant correlation of learners' personality characteristics to diverse learning parameters (academic performance, learning achievement, learning motivation, online course impressions, learning styles, learning approaches, etc.) which demonstrates the necessity to learn about students' personality to support them efficiently during their learning activities (Ariani, 2013; Jensen, 2015; Chue, 2015; Zhou, 2015; Xie, \& Zhang, 2015; Al-Naggar, Osman, Ismail, Bobryshev, Ali, \& Menendez-Gonzalez, 2015; Zhou, \& Intaraprasert, 2015; Ghazi, Shahzada, \& Ullah, 2013; Ibrahimoglu, Unaldi, Samancioglu, \& Baglib el, 2013; Harley, Carter, Papaionnou, Bouchet, Landis, Azevedo, \& Karabachian, 2016; Komarraju, Karau, Schmeck, \& Avdic, 2011; Pornsakulvanich et al., 2012; Sahinidis, Frangos, \& Fragkos, 2013; Shahri, Javadi, \& Esmael, 2012). These scholars, as well as, others show how important to change the traditional "one-size-fits-all" educational system to respond to learner's individual characteristics and needs. Actually, students cannot be educated with the same pacing, resources, and instructional pedagogy due to their diversity.

For instance, (Al-Dujaily, Kim, \& Ryu, 2013) show the impact of personality traits (introversion vs. extroversion) on learners' motivation and ability to learn with adaptive elearning system. Such empirical works constitute theoretical basis for applications tending to develop classrooms that are student-centered (EI Bachari, Abdelwahed, \& El Adnani, 2010; Fatahi, Kazemifard, \& Ghasem-Aghaee, 2009; Fatahi, Moradi, \& Kashani-Vahid, 2016; Faria, Almeida, Martins, Gonçalves, \& Figueiredo, 2015).

Researchers in education emphasize the importance to consider learners' personality differences in teaching which can lead consequently to student's positive academic outcomes (Ambrose \& Lovett, 2014; Seifert \& Sutton, 2009).

In the digital era, organizations and institutions are increasingly moving toward adopting distance learning. Several works show the students' positive attitudes and views towards distance education (Gurbuz, 2014; Sad, Goktas, \& Bayrak, 2014; Stanley, 2015; Chong, Francis, Cooper, Abdullah, Hmwe, \& Sohod, 2016). The online method of learning uses the web as the medium for delivering instruction to a remote audience, so it is challengeable to diversify instructions according to students' characteristics. To do so, we need to implement effective online instructional systems based on proven and sound theories from science of learning and to have a full imagine of any learner as a way for personalizing, monitoring and evaluating online teaching process.

By reference to the richer literature on relation between personality and learning process, experts in e-learning domain suggest that the attractiveness of virtual learning environments would be increased by inserting the human personality characteristics in these environments. For instance, (Fatahi et al., 2009) propose a new model presented according to the learning model based on emotion, personality and the model of virtual classmate. In first step, the proposed system identifies learner's personality using the Myers-Briggs Type Indicator (MBTI) questionnaire. Thereafter, the virtual teacher and classmate express suitable instructional behaviors to improve the learning process according to the identified learner's personality model and emotional status. The experimental results show the significance of the proposed instructional approach to increase learning quality and to satisfy learners. (Abrahamian, Weinberg, Grady, \& Stanton, 2004) show the significant effect of personality-aware human-computer interface on learning process. Indeed, the authors design a set of user interfaces which fit personality types identified using the MBTI test. Then, they provide a given user interface to participants with the matching personality type. They find that users prefer user interfaces designed for their own personality type. This finding indicates the positive effect of personality-aware user interfaces on learning. (EI Bachari et al., 2010) suggest an Adaptive e-learning model based on learner's personality. The proposed system uses the MBTI psychometric test to recognize learner's personality and suggests a learning style that matches his preferences. 
The previous works have mostly relied on self-report measures to explicitly acquire users' personality, which unavoidably demands user efforts. From users' perspective, they are sometimes unwilling or unable to provide accurate reports of their own psychological attributes or just unwilling to answer the quiz for the sake of saving efforts or protecting their privacy. This method of personality measure has a potential inaccuracy because of its lack of objectivity and a bias due to cultural influences. To overcome these limitations, we are motivated, in this study, to show how to implicitly derive users' personality from their behavior data. While personality manifests itself in an abundance of cues, this work focuses only on cues from reading and writing behaviors. Specifically, we are interested to personality computing based on users' annotation cues.

The layout of the remainder of this study is as follows. First, we present the credibility issue of learner's personality modeling in online learning context. Then, we show reader's personality markers in handwritten annotations. Thereafter, we propose a computational model used to recognize learners' personality traits through their digital annotations. Next, we evaluate the system's performance to measure accurately the Big Five scores of learners' traits. Finally, we discuss our results, we draw some conclusions and we suggest certain possible directions for future works.

\section{ISSUE OF MODELING LEARNER'S PERSONALITY IN ONLINE LEARNING CONTEXT}

Although the findings of previous works are fruitful, we believe these researches have left certain open issue related to the followed approach to collect required data to model learners' personality profiles. In distance learning context using psychometrics standards' which are a standards and scientific methods used to measure individuals' mental capabilities, behavioral style and personality traits, to determine learners' personality has many challenging aspects related to the validity of self-reported data. The crucial aspect to consider in user profiling process, is to model a credible student's profile that reflects truly learner's characteristics in the online learning environment (Chieu, Luengo, Vadcard, \& Tonetti, 2010; Gong, Beck, \& Heffernan, 2011; Lintean, Rus, \& Azevedo, 2012). The contact with test-takers using online psychometric tests is indirect, and because of the diminished control over the testing situation, there is no way to confirm that they have understood instructions and/or items correctly or to provide them with ongoing guidance (Barak, 1999). This situation may affect the reliability of the test results. Furthermore, the users tend usually, to preserve their privacy over web, and they are not ready to reveal their personalities information through filling psychometric forms. Consequently, the testtakers, either, do not fill the forms or cheat the answer when the motivation to do is obvious (Barak, Buchanan, Kraus, Zack, \& Stricker, 2004). According to psychology experts, the personality tests are designed to be administered under controlled and standardized conditions which are not the case of the Web-based assessments tests (Barak et al., 2004). As a way to collect a credible data from people, certain psychologists seek to alternative measurement instruments that reduce participants' ability to control their responses and do not require introspection for the assessment of psychological attributes (Gawronski \& De Houwer, 2014).

Several works shed the light on the possibility of personality computing through users' observed actions or their captured digital behavioral-residues in different on-line working environments. In this scope, there is an increasing interest in understanding human perception based on reading and writing behaviors. Many researchers are interested to study the ability to profile users' personality from human text production and peculiarities of reading behaviors. For instance, (Celli, 2012; Mairesse, Walker, Mehl, \& Moore, 2007; Wright \& Chin, 2014) show the opportunity to derive users' personality from text and linguistic cues. Further works suggest extracting personality traits from users' hand writing (Fisher, Maredia, Nixon, Williams, \& Leet, 2012; Grewal \& Prashar, 2012; Prasad, Singh, \& Sapre, 2010; Rahiman, Varghese, \& Kumar, 2013). Other researchers are interested to extract users' trait from posts written in online social spaces (Iacobelli, Gill, Nowson, \& Oberlander, 2011; Sumner, Byers, Boochever, \& Park, 2012). (Mezghani, Zayani, Amous, \& Gargouri, 2012) propose to derive personality from social annotations and (Jackson, 2001; 
Omheni, Mazhoud, Kalboussi, \& HadjKacem, 2014) show the relation between readers' personality and their annotation traces made during reading activity.

We aim by the current work to present new mythology of personality modeling in computer-based learning systems. Our goal is to increase the credibility of learner's personality profile by computing the required data, implicitly, based on learner's observed annotation traces.

\section{PERSONALITY MARKERS IN ANNOTATIONS}

Annotation is a handwritten practice which bridges between reading and writing (Marshall, 1998) and constitutes the most prominent habit of reading activity (Lamb, 2007). The annotation activity is "basic and often unselfconscious ways in which readers interact with texts" (Marshall, 2009, p. 38). Furthermore, the annotation is described as a natural human activity that is used in daily life as an integral part of reading activity (0'hara \& Sellen, 1997). Kirwan (2010, p. 5) considers reader's marginalia (annotations) as: the "most direct, reactionary response to the text that can feasibly be considered" to study the relation between the reader identity and the text. According to (Kirwan, 2010), annotations provide the link between reader, text, and meaning and reflect the subjective individuality of the annotator's responses to the text. Based on this subjective relationship, the author suggests expanding the psychology-based reader theory to include reader's annotation practices.

Every annotator has unique individual patterns in making annotations (Naghsh, 2007). According to (Jackson, 2001, p. 5), "if you ask annotators today what systems they use for marking their books and where they learned them, they generally tell you that their methods are private and idiosyncratic". Hence, the individuality of annotation patterns shows that there can be some sort of connection between annotation practices and annotator's personality. (Jackson, 2001, p. 87) assumes that "marginalia [annotations] express a reader's impulsive and unguarded reactions to a book" and she "consider[s] them to be an exceptionally reliable guide to personality".

In this essay we suggest utilizing digital annotations to compute learner's personality in online learning environment. In what follow, we explain which type of personality trait we are going to take into account in our study. Then we present our prior work that shown the connection relation between learners' personality and their handwritten annotations.

\section{The Big Five Personality Model}

The big five personality model is the best accepted and most commonly used scientific measure of personality that has been extensively researched (Peabody \& De Raad, 2002). Human personality is well described as five traits were discovered through the study of adjectives from natural language that people used to describe themselves. The five traits representing the main personality dimensions are: Openness to Experience, Conscientiousness, Extraversion, Agreeableness, and Neuroticism.

\section{Prior Work}

In prior work, we conducted an empirical study to show the implicit relation between the reader's annotations and his personality traits (Omheni et al., 2014). We consider a sample of 120 volunteers. The subjects selected were recruited with respect to certain criteria. In fact, the volunteers' ages are equal or superior to 18 and they have different occupations and interests. In our sample we have the two sexes (44 women and 76 men). Furthermore, all the participants have the habit to annotate their documents while reading. Each subject was instructed to answer a standard Five Factor Model questionnaire (the NEO-IPIP Inventory). This step gives us the personality scores based on the Big Five Model for each volunteer. To associate personality scores to subjects' annotative activities, we gathered annotation practices for each participant and we collected a simple set of statistics about his annotative activity (TNAA: Total Number of Annotation Act; ANAA: Average Number of 
Annotation Act; NGAA: Number of Graphical Annotation Act; NTAA: Number of Textual Annotation Act; NRAA: Number of Reference Annotation Act; NCAA: Number of Compounding Annotation Act). The set of statistics tends to characterize quantitatively the reader's annotation practices. We studied the Pearson correlation between subjects' personality scores and each of the features obtained from analyzing their annotative activities. We reported the correlation values in table 1.

Table: 1

Pearson Correlation Values Between Scores of Annotation Features and Personality Traits

\begin{tabular}{lccccc}
\hline Variables & Openness & Conscientiousness & Extraversion & Agreeableness & Neuroticism \\
\hline TNAA & -.059 & .128 & -.138 & .089 & $-.287^{*}$ \\
ANAA & .003 & .080 & $-.210 *$ & .163 & $-.183^{*}$ \\
NGAA & -.067 & .040 & -.130 & .105 & $-.207^{*}$ \\
NTAA & .001 & $.182 *$ & .040 & .085 & $-.211^{*}$ \\
NRAA & -.075 & .045 & -.122 & .077 & $-.207^{*}$ \\
NCAA & -.059 & .012 & -.147 & .014 & $-.219 *$ \\
\hline & Note. ${ }^{*} \mathrm{p}<.05$ & & & &
\end{tabular}

Conscientiousness is positively related to number of textual annotations. The rest of the correlation values are not considerate because of $p$-value $\mathbf{> 0 . 0 5}$. But this is not a reason to reject definitively the rest of annotation features as a larger sample size may produce other significant correlations. Extraversion is negatively correlated with the average number of annotation act. Neuroticism is negatively correlated with all the annotation features. Here, the sample size is sufficient to procure significant correlations for all the considered features.

Furthermore, we make predictions about subject's personality based on multiple annotation features. Our findings show that Neuroticism and Conscientiousness can be predicted with reasonable accuracy using the different annotation features, whereas other traits are more difficult to be predicted (Table. 2). Based on the values of the coefficient of multiple determinations $\boldsymbol{R}^{2}$ which measures the strength of the correlation fit and the Ftest which measures the statistical significance of the collective influence that have the annotation features on the personality traits presented in table 2 , we show that prediction regarding Conscientiousness is reasonably accurate, with $R^{2}$ value of $0.12, F_{\text {observed }}$ value of 2.52 which exceeds $F_{\text {critical }}$ value and $\mathbf{P}$-value of 0.03 which is lower than $\boldsymbol{a}$ value where $\mathbf{P}$ value is the probability of the F-test statistic is larger than the observed F-value. For Neuroticism we obtained the model with the best fit, with an $R^{2}$ value of $0.14, F_{\text {observed }}$ value of 3.11 and $P$-value of $\mathbf{0 . 0 1}$, indicating quite accurate prediction. The model for Extraversion has a lower fit and the model for Agreeableness is even less accurate. It seems that Openness is the hardest trait to predict using annotation features. 
Table: 2

Predicting Personality Traits Using Annotation Features through Multivariate Linear Regression

\begin{tabular}{llcc}
\hline Personality Trait & $\boldsymbol{R}^{2}$ & F-test & P-value \\
\hline Openness & .03 & .57 & .76 \\
Conscientiousness & .12 & 2.52 & $.03^{*}$ \\
Extraversion & .07 & 1.32 & .25 \\
Agreeableness & .05 & 1.03 & .41 \\
Neuroticism & .14 & $\mathbf{3 . 1 1}$ & $.01^{*}$ \\
\hline Note. ${ }^{*}<.05$ & & &
\end{tabular}

\section{EXTRACTION OF LEARNER'S PERSONALITY TRAITS FROM DIGITAL ANNOTATIONS}

Based on what previously cited, it is plain that reader's annotation is really an expression of his personality traits. Indeed, we show very plainly that the considered annotation features in our study may appear insignificant in them-selves, but, they are nevertheless all very significant as indications of the annotator's personality traits.

Recent researches endeavor to replace the "pen-and-paper" paradigm for the annotation needs by employing the technology of free form digital ink annotations which add the flexibility and natural expressiveness of the traditional handwriting method to the digital annotation process. Such tools enable readers to annotate their digital documents similarly to "pen-and-paper" case. These tools refer to user studies examining the paper-based annotation that analyze readers' annotation behavior during the learning process (Nunes, Kawase, Dietze, de Campos, \& Nejdl, 2012; Steimle, Brdiczka, \& Mühlhäuser, 2009). Such works provide several insights to fully comprehend the desired annotation features needed on the digital support. Hence, the digital annotation context becomes very similar to the context of "pen-and-paper". Due to the proximal similarity among these two contexts, we are motivated to apply our previous findings in the digital context to automatically predict users personality traits based on their annotations.

The proposed system called "i-Read" is an online reading environment where learners can upload their reading materials, practice their habit of annotation and share their annotated documents with others. Figure 1 illustrates interactions between the various modules of " $i$ Read" system along with the flow of data. The system's architecture consists of user annotation interface, the annotation analyzer module, the profile constructor module and three databases with two servers. To avoid destroying the original version of reading materials, our system uses an independent annotation database, which differs from the documents database, to store annotations' parameters and contexts from learners. The annotation interface provides several powerful annotation functionalities, such as scribbling, highlighting, underlining, commenting, as a way to engage users actively with their reading contents. 


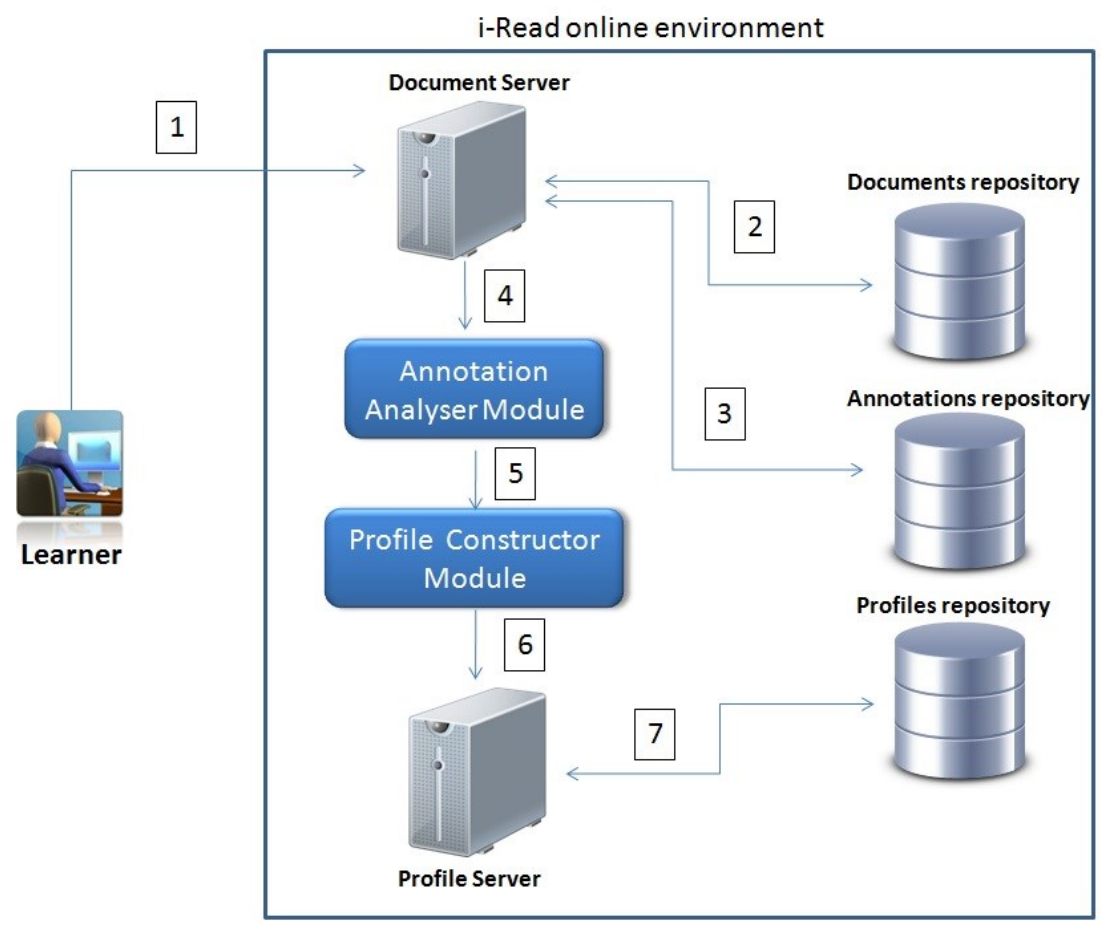

Figure: 1

The "i-Read" Architecture System

\section{The Annotation Analyzer Module}

This module is used to observe reader's annotations yielded during a reading session and to compute certain parameters related to the total number of annotations, average number of annotations (number of annotation per one page of document reading), number of graphical annotations, number of referential annotations, number of textual annotations and number of composed annotations. The Annotation Analyzer Module tracks annotations of the connected user and stored them in a relational database. In our concept, a user annotation trace is an act that affects an element of the document reading. The annotations are tracked and stored with their parameters which are the following:

1. Target: contains the values of coordinate points that define the annotated element in the logical structure of document reading,

2. Body: the content of the annotation trace

3. Sign: we classify annotations in three general categories. This categorization is based on how annotations can appear and be represented: (a) textual annotation expressed by a piece of text added to the annotated document; (b) graphic annotation expressed by a graphic mark added to a document; (c) reference annotation expressed by a link between two texts or two textual pieces in the same document.

Agosti \& Ferro (2003) called the three categories of visual signs as the basic ways to represent annotations. Furthermore, they define the term sign as a formation of a meaning that can be combined together to express more complex signs of annotation.

In our work, we consider the annotation sign parameter as the main characteristic which constitutes the cornerstone to study quantitatively the digital annotation activity. In fact we compute certain features with reference to the visual sign of annotation traces (graphic, text, reference, composed). Technically, to implement the system annotation tool, we refer to Annotator.js library. The annotation model adopted in our work follows a simple JSON format with three fields: 


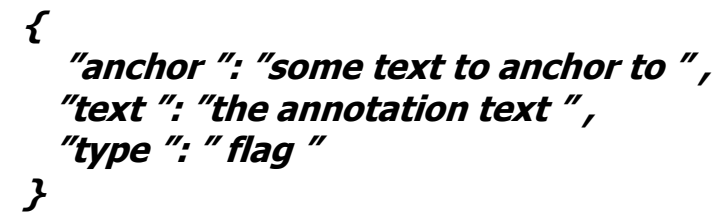

Where "anchor" (target) is the specifications used to position the annotation on the reading material. Technically, we have used the anchoring strategy inherited from the Annotator project, which anchors annotations to their targets by saving exact locations in the form of $X P a t h$ range descriptions to the involved DOM elements and the string offsets inside them. When the anchor needs to be located again, the DOM elements are found by using the same XPath expressions. Regarding the other annotation's parameters, "text" is the body of the annotation to show, and "type" (sign) is the kind of annotation.

\section{The Profile Constructor Module}

The profile constructor module is used to predict readers' personality scores through their observed annotations. To compute user's traits we utilize the multivariate linear regression algorithm. The following equation represents the mathematical format of the collective influence of the considered annotations' features on one single personality traits.

$$
Y=b_{0}+b_{1} X_{1}+b_{2} X_{2}+b_{3} X_{3}+b_{4} X_{4}+b_{5} X_{5}+b_{6} X_{6}
$$

$Y$ is the predicted or expected value of the dependent variable representing the score of the focused user's personality trait. $X_{1}$ through $X_{6}$ are the distinct independent or predictor variables representing the different annotation features considered in our study. $b_{0}$ is the value of $Y$ when all of the independent variables ( $X_{1}$ through $\left.X_{6}\right)$ are equal to zero. $b_{1}$ through $b_{6}$ are the estimated regression coefficients. Based on this mean function, we can determine the expected annotator's personality trait as long as we know certain peculiarities characterizing quantitatively his annotation practices. We cite in table 3 the different estimated regression coefficients used to predict scores of reader's traits given the values of the different considered features ( $x$ variables).

Table: 3

The Regression Coefficients Used to Predict the Score of Reader's Traits

\begin{tabular}{lcc}
\hline Independent Variables & Conscientiousness & Neuroticism \\
\hline Intercept $\left(b_{0}\right)$ & 21.82 & 70.06 \\
Number of Graphical Annotations $\left(b_{1}\right)$ & .66 & .18 \\
Number of Reference Annotations $\left(b_{2}\right)$ & -.02 & -.13 \\
Average Number of Annotations $\left(b_{3}\right)$ & .14 & 0 \\
Total Number of Annotations $\left(b_{4}\right)$ & -.81 & -.38 \\
Number of Textual Annotations $\left(b_{5}\right)$ & .32 & -.06 \\
Number of Compounding Annotations $\left(b_{6}\right)$ & 0 & 0 \\
\hline
\end{tabular}

\section{System Operation Procedure}

Based on the system architecture (Fig.1), the functional scenario of "i-Read" system is described and summarized as follows. First of all, the learner should connect to " $i$-Read" environment to upload his reading document. In second step, the system saves the document in the documents repository. Thirdly, the learner can start reading and annotating his document. Fourthly, the system saves learner's annotations in the Annotations repository. In fifth step, the annotation analyzer module captures learner's annotations and extracts certain quantitative features. Sixthly, the annotation analyzer 
module sends the computed information to the profile constructor module to build learner's personality profile. Seventhly, the profile constructor module considers the received information as an input data to the multivariate linear regression algorithm used to estimate scores of learner's traits. Finally, the system saves the modeled user's profile in the Profiles repository.

\section{EVALUATION OF "I-READ" SYSTEM'S PERFORMANCE}

In this section, we are interested to check the performance of our system for personality recognition compared to the Neo-IPIP inventory which is the most scientifically based test of personality traits, and is generally accepted worldwide as one of the more highly regarded, and accurate, personality questionnaires.

\section{Participants}

We recruited 100 volunteers ( 35 women and 65 men) aged between 22 and 50 years. Most of the participants have the professorship degree in scientific or literary disciplines. All the invited people have participated in our prior experimentation. We have the decision to reinvite the same people because they have the required criteria to participate in present experimentation. Indeed, they are academic people who have the habit to annotate documents while reading. The majority of the selected participants are graduates. Generally, this category of people is serious and motivated to make annotations during their reading activities. Furthermore, they are good practitioners of annotations and conscious of its efficiency in academic achievement and learning performance.

\section{Procedure}

We instructed the participants to upload their textual materials on the "i-Read" environment and to use the system to achieve their reading and annotation activities (Fig.2). The volunteers are free to select their reading contents that interest them and the text's written language (English, Arabic or French) all depends to their linguistic skill. The sample members did not differ on their reading comprehension abilities. The majority of participants indicated that they had prior knowledge in the topic of their reading materials. The selected documents aren't hard, so they didn't need much cognitive effort from readers' side. We consider all the previous conditions because we are very careful to the comfortability of participants during their reading activities. These conditions may guarantee their spontaneous and natural reactions. In the second step, we instructed participators to answer the standard Five Factor Model questionnaire (NEO-IPI P Inventory) to compute scores of their personality traits. In third step, we are interested to evaluate system's performance to compute accurately learner's scores of conscientiousness and neuroticism traits compared to the values determined using the NEO-IPIP Inventory. We applied the Pearson Product Moment Correlation to measure the linear correlation between the traits scores obtained through the two different systems. We also measure the root-mean-square error (RMSE), which are the root mean squared differences between predicted values (scores measured with i-Read system) and observed values (scores measured with Neo-ipip inventory). 


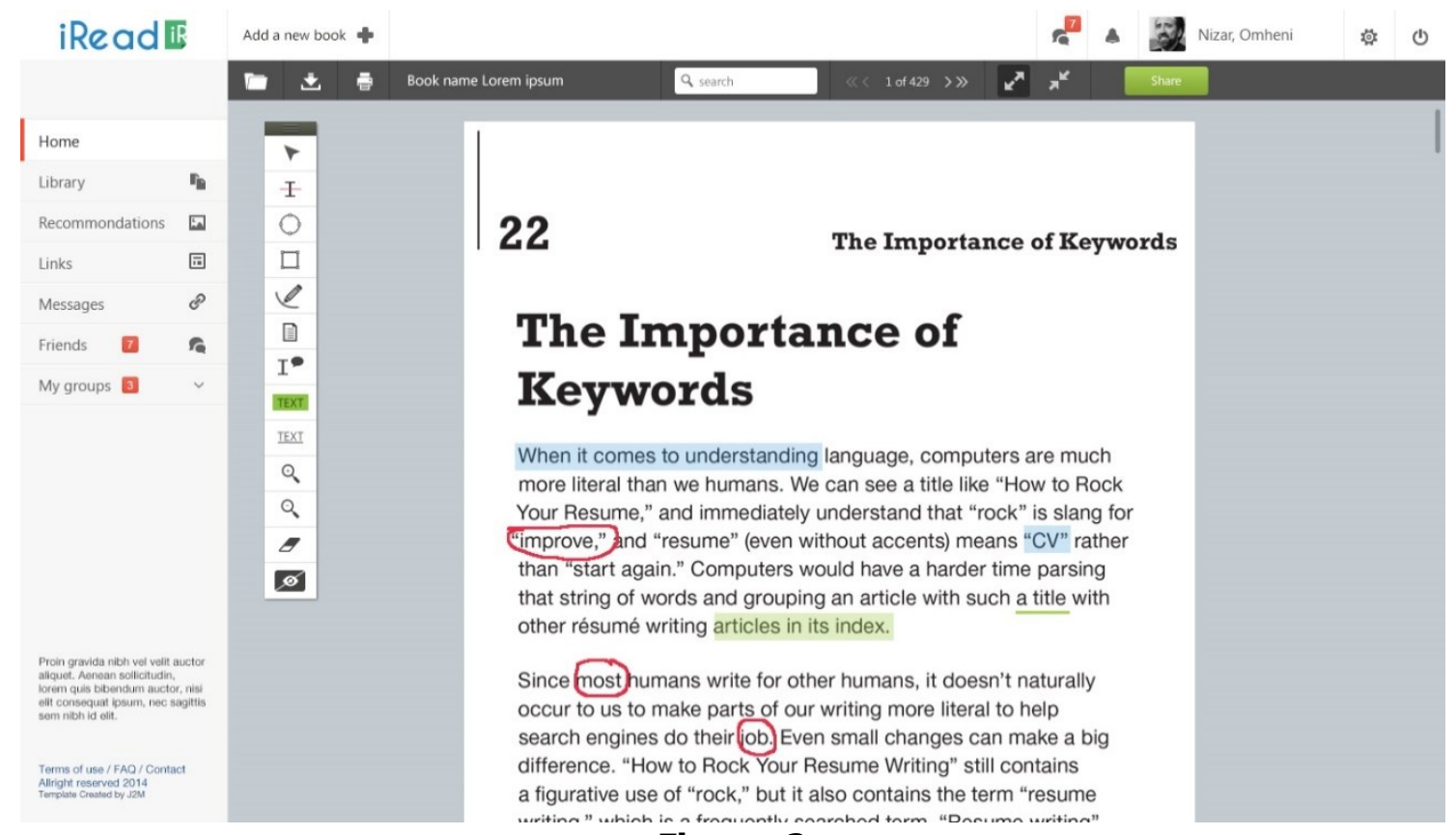

Figure: 2

Annotated Document on "i-Read" online Environment

\section{RESULTS and DISCUSSION}

We report the statistical coefficients values in table 4 and 5 for the conscientiousness and neuroticism traits respectively. Given that correlations are significant $(p<0.05)$ for both consciousness and neuroticism traits and the lower values of RMSE and Mean, we show the regression models for the considered personality traits are well-fitting and the predicted values close to the observed data values which means that there is no significant difference between the scores of user's personality traits computed using the "i-Read" system and those measured using the Neo-IPIP inventory.

Table: 4

Linear Correlation Coefficients of the Conscientiousness Scores Measured With Two Different Systems

\begin{tabular}{lccc}
\hline Scores measured with & Mean & RMSE & P-value \\
\hline "i-Read" system &. &. &. \\
Neo-IPIP inventory & .02 & .10 & $.03 *$ \\
\hline Note. ${ }^{*}$ < $<.05$ & & &
\end{tabular}

Table: 5

Linear Correlation Coefficients of the Neuroticism Scores Measured With Two Different Systems

\begin{tabular}{lccc}
\hline Scores measured with & Mean & RMSE & P-value \\
\hline "i-Read" system &. &. &. \\
Neo-IPIP inventory & .03 & .10 & $.01 *$ \\
\hline Note. *p<.05 & & &
\end{tabular}

Several works interested to design personality-based online learning systems utilize classical methods to recognize learners' personalities which tend to focus on questionnaires. Such works enter their participants into a cash prize draw to externally motivate them toward the experimental task (Al-Dujaily et al., 2013; Kim et al., 2013). Without such external motivational acts, learners are not ready to answer a range of $\mathbf{4 0}$ or more questions about their personality information. Usually, learners prefer to preserve 
their privacy and refuse communicate their personal information with third party. Personality recognition based on learners' annotations is not presented here as a replacement for psychometric tests, but rather as additional information that may help combat some of the difficulties encountered with questionnaires. Possibly the biggest advantage is that personality traits measurement through annotation traces can be taken in parallel with the interaction rather than wearying the learner to answer a long form or too many questions.

On the other hand, based on our findings, we show the neuroticism trait is negatively correlated to the different annotation features considered in our study. This result clearly indicates that learners with high level of emotional stability are more productive of annotation traces which reflect their deep reading of textual material. Thus, those who have low score of neuroticism are more stable and they have the ability to focus more on their current activities and they can deal with reading materials qualified with high level of complexity. Regarding the consciousness trait, we show this trait is correlated positively to annotation features. This evidence reflects that conscientious learners produce more annotation traces during their reading. We may interpret the case that learners who have high degree of conscientiousness choose to read their reading materials deeply.

Based on previous interpretations, we believe that learners with high degree of consciousness and high level of emotional stability are more able to deal with hard textual materials through using annotation skill, knowing that the process of annotation is viewed as learning strategy used to improve reading comprehension and favors deeper processing and understanding of text (Brahier, 2006; Brown, 2007; Huang, 2014; Porter-O'Donnell, 2004). For those who have low level of consciousness and high level of anxiety should be treated carefully to enhance their reading comprehension performance. These evidences may be viewed as guide to design personality-based learning system of online reading classes. Actually, many learning systems offer annotation functionalities to their users to increase their reading performance (C.-M. Chen et al., 2012, 2014; Yueh et al., 2012). Such works show the efficiency of annotation tools to enhance users' learning experience. We think that our work is step forward for these works to use annotation traces as indicator of learners' personality traits that reflects their reading performance level. This information may be helpful to assist learners having difficulties in reading comprehension. Finally, although our results are promising and constitute a new tendency in computing learners' personality traits based on their behavioral residues of reading and writing activities in online learning environment, some limitations need further consideration. The most important issue is the sample size as we expect more significant results around the relation between annotations and readers' traits (agreeability, extraversion and openness) with a larger sample. On the other hand, we limited our study to graduate students with experience in annotation. This point can be viewed as a limitation of our study. But, right now, we try applying our findings to design adaptive personality-based learning strategies to help students enhancing their reading performance and to assist them during their learning experience. In this future work, we are interested to normal students who may have or not experience in annotation. Furthermore, our study is based on linear correlation model, but digital annotations and personality may not be linearly correlated. This consideration may be viewed as limitation of current work. We expect trying advanced nonlinear models, or polynomial regression in future works. Also our research can be extended to study the influence of readers' demographic characteristics (gender, age...) and further factors which may, likely, influence annotation behavior such as familiarity with annotation tools and interest in the content topic. 


\section{CONCLUSION}

This study investigates the possibility of personality recognition based on digital annotations. This is a new tendency in personality-computing research area and a step forward for indirectly assessing learners' personality in online learning environment. The relation between learners' personality traits and their annotation activities may reflect their reading performance level, which is helpful to assist students who have difficulties in reading comprehension. To overcome shortcomings of reading online, we try to design a collaborative learning system which enables students to upload, annotate and share their personal reading experiences. This strategy has the potential to facilitate understanding of reading texts and helps to develop a reader into a writer and promote collaborative learning. We suggest classified learners, according to their scores of neuroticism and consciousness traits, to good reader, ordinary reader, and poor reader. Those suffering of reading comprehension will receive the annotations of skilled readers. In "i-Read" reading environment there is no instructors, just the students teach each other through sharing their learning experiences and knowledge. In future paper we'll give more details about this work and the conducted experiments to show the efficiency of the proposed approach to support learners with low online reading abilities.

\section{BIODATA and CONTACT ADDRESSES of the AUTHORS}

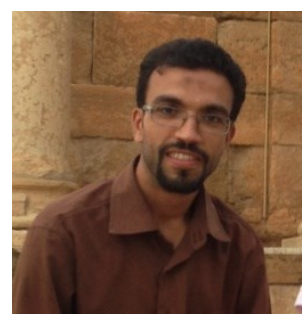

Nizar OMHENI is Ph.D student at Faculty of Economics and Management, University of Sfax. He is a member of ReDCAD Laboratory, National School of Engineers of Sfax Department of Computer Science and Applied Mathematics. Omheni is Assistant Professor at High Institution of Computer Sciences and Management of Kairouan University.

Nizar OMHENI

Sahabi 4 city, Ukranian Street, House n69, Kairouan 3100.

Phone: +216 29214107 / +216 58914107

e-Mail: nizar.omheni@isigk.rnu.tn

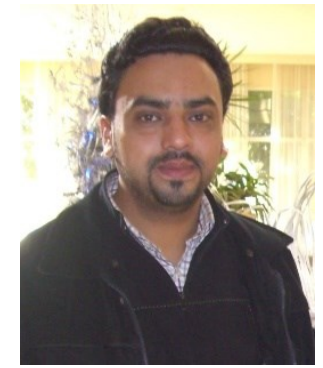

Anis KALBOUSSI received his Master's degree and his PhD in Computer Science from the Higher Institute of Computer Science and Management of Kairouan and the Faculty of Economics and Management of Sfax in 2011 and 2015, respectively. He is currently an Associate Professor in Computer Science at the University of Kairouan, Tunisia. He is a member of the ReDCAD Research Laboratory. His current research areas include Technology Enhanced Learning, Semantic Web, Personal Information Management, Web Services, and Metadata-annotation.

\section{Anis KALBOUSSI}

Higher Institute of Computer Science and Management, Street of Khmais Alouini, Tunisia, Kairouan 3100, TN.

Phone: +216 23443099

e-Mail: anis.kalboussi@isigk.rnu.tn 


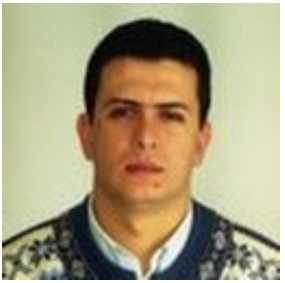

Omar MAZHOUD is Assistant Professor at High Institution of Computer Sciences and Management of Kairouan. He is Ph.D student at Faculty of Economics and Management, University of Sfax. Mazhoud is a member of ReDCAD Laboratory, National School of Engineers of Sfax, Department of Computer Science and Applied Mathematics.

Omar MAZHOUD

Street Khmaies Alouini Tunisia, Kairouan 3131, TN

Phone: +216 98830967

e-Mail: omar.mazhoud@isigk.rnu.tn

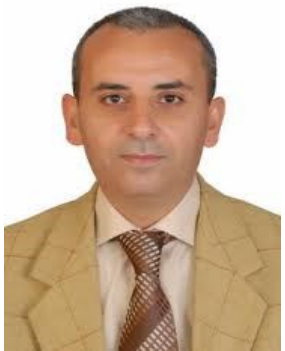

Ahmed Hadj KACEM is Professor in Computer Science at the Faculty of Economics and Management of Sfax University. He is Director of Faculty of Economics and Management, University of Sfax. He is a member of ReDCAD laboratory, Department of Computer Science and Applied Mathematics National Engineering School of Sfax (ENIS), University of Sfax, Tunisia ACM professional member. Kacem is IEEE professional member (Computer Society).

\section{Ahmed Hadj KACEM}

Faculty of Economics and Management, University of Sfax, ReDCAD Laboratory, Road of the Airport Km4Tunisia, Sfax 3018, TN Phone: +216 98511100

e-Mail: ahmed.hadjkacem@fsegs.rnu.tn

\section{REFERENCES}

Abrahamian, E., Weinberg, J., Grady, M., \& Stanton, C. M. (2004). The effect of personality-aware computer-human interfaces on learning. Journal of universal computer science, 10(1), 27-37.

Agosti, M. \& Ferro, N. (2003). Annotations: enriching a digital library. In Research and advanced technology for digital libraries (pp. 88-100). Springer.

Al-Naggar, R. A., Osman, M. T., Ismail, Z., Bobryshev, Y. V., Ali, M. S., \& MenendezGonzalez, M. (2015). Relation between Type of Personality and Academic Performance among Malaysian Health Sciences Students.International Archives of Medicine, 8.

Ambrose, S. A. \& Lovett, M. (2014). Prior knowledge is more than content: skills and beliefs also impact learning. In Applying science of learning in education: infusing psychological science into the curriculum (pp. 7-19). the American Psychological Association.

Ariani, D. W. (2013). Personality and learning motivation. European Journal of Business and Management, 5(10), 26-38.

Barak, A. (1999). Psychological applications on the internet: a discipline on the threshold of a new millennium. Applied and Preventive Psychology, 8(4), 231-245.

Barak, A., Buchanan, T., Kraus, R., Zack, J., \& Stricker, G. (2004). Internet-based psychological testing and assessment. Online counseling: A handbook for mental health professionals, 217-239. 
Brahier, B. (2006). Teachers' uses of students' digital annotations: implications for the formative assessment of reading comprehension. University of Minnesota Center for Reading Research, Minneapolis, MN.

Brown, M. D. (2007). I'll have mine annotated, please: helping students make connections with texts. English Journal, 73-78.

Celli, F. (2012). Adaptive personality recognition from text (Doctoral dissertation, University of Trento).

Chen, Y.-C., Hwang, R.-H., \& Wang, C.-Y. (2012). Development and evaluation of a web 2.0 annotation system as a learning tool in an e-learning environment. Computers \& Education, 58(4), 1094-1105.

Chen, C.-M., Chen, Y.-T., Hong, C.-M., Liao, C.-W., \& Huang, C.-M. (2012). Developing a taiwan library history digital library with reader knowledge archiving and sharing mechanisms based on the dspace platform. The Electronic Library, 30(3), 426-442.

Chen, C.-M., Wang, J.-Y., \& Chen, Y.-C. (2014). Facilitating english-language reading performance by a digital reading annotation system with self-regulated learning mechanisms. Journal of Educational Technology \& Society, 171), 102-114.

Chieu, V. M., Luengo, V., Vadcard, L., \& Tonetti, J. (2010). Student modeling in orthopedic surgery training: exploiting symbiosis between temporal Bayesian networks and finegrained didactic analysis. International Journal of Artificial Intelligence in Education, 20(3), 269-301.

Chong, M. C., Francis, K., Cooper, S., Abdullah, K. L., Hmwe, N. T. T., \& Sohod, S. (2016). Access to, interest in and attitude toward e-learning for continuous education among Malaysian nurses. Nurse education today, 36, 370-374.

Chue, K. L. (2015). Examining the influence of the big five personality traits on the relationship between autonomy, motivation and academic achievement in the twenty-firstcentury learner. In Motivation, leadership and curriculum design (pp. 37-52). Springer.

Al-Dujaily, A., Kim, J., \& Ryu, H. (2013). Am i extravert or introvert? considering the personality effect toward e-learning system. Journal of Educational Technology \& Society, 16(3), 14-27.

El Bachari, E., Abdelwahed, E. H., \& El Adnani, M. (2010). Design of an adaptive e-learning model based on learner's personality. Ubiquitous Computing and Communication Journal, 5(3), 1-8.

Faria, A. R., Almeida, A., Martins, C., Gonçalves, R., \& Figueiredo, L. (2015, July). Personality traits, Learning Preferences and Emotions. In Proceedings of the Eighth International C* Conference on Computer Science \& Software Engineering (pp. 63-69). ACM.

Fatahi, S., Kazemifard, M., \& Ghasem-Aghaee, N. (2009). Design and implementation of an elearning model by considering learner's personality and emotions. In Advances in electrical engineering and computational science (pp. 423-434). Springer.

Fatahi, S., Moradi, H., \& Kashani-Vahid, L. (2016). A survey of personality and learning styles models applied in virtual environments with emphasis on e-learning environments. Artificial Intelligence Review, 1-17.

Fisher, J., Maredia, A., Nixon, A., Williams, N., \& Leet, J. (2012). Identifying personality traits, and especially traits resulting in violent behavior through automatic handwriting analysis. In Proceedings of student-faculty research day, csis. Pace University. 
Gawronski, B. \& De Houwer, J. (2014). Implicit measures in social and personality psychology. Handbook of research methods in social and personality psychology, 2.

Ghazi, S. R., Shahzada, G., \& Ullah, S. (2013). Relationship between students' personality traits and their academic achievement in khyber pakhtunkhwa, pakistan. Journal of Educational and Social Research, 3(2), 437.

Gong, Y., Beck, J. E., \& Heffernan, N. T. (2011). How to construct more accurate student models: comparing and optimizing knowledge tracing and performance factor analysis. International Journal of Artificial Intelligence in Education, 21 (1-2), 27-46.

Grewal, P. K. \& Prashar, D. (2012). Behavior prediction through handwriting analysis. International Journal of Computer Science and Technology \{IJCST\} ISSN: 2229, 4333.

Gurbuz, F. (2014). Students' views on distance learning in turkey: an example of anadolu university open education faculty. Turkish Online Journal of Distance Education, 15(2).

Harley, J. M., Carter, C. K., Papaionnou, N., Bouchet, F., Landis, R. S., Azevedo, R., \& Karabachian, L. (2016). Examining the predictive relationship between personality and emotion traits and students' agent-directed emotions: towards emotionally-adaptive agent-based learning environments. User Modeling and User-Adapted Interaction, 1-43.

Huang, W.-C. (2014). The effects of multimedia annotation and summary writing on taiwanese efl students' reading comprehension. Reading, 14 (1).

Iacobelli, F., Gill, A. J., Nowson, S., \& Oberlander, J. (2011). Large scale personality classification of bloggers. In Affective computing and intelligent interaction (pp. 568-577). Springer.

Ibrahimoglu, N., Unaldi, I., Samancioglu, M., \& Baglibel, M. (2013). The relationship between personality traits and learning styles: a cluster analysis. Asian Journal of Management Sciences and Education, 2(3).

Jackson, H. (2001). Marginalia: readers writing in books. Nota Bene series, Yale University Press.

Jensen, M. (2015). Personality Traits, Learning and Academic Achievements.Journal of Education and Learning, 4(4), 91.

Kim, J., Lee, A., \& Ryu, H. (2013). Personality and its effects on learning performance: design guidelines for an adaptive e-learning system based on a user model. International Journal of Industrial Ergonomics, 43(5), 450-461.

Kirwan, K. (2010). Rebellious readers: a marginalized reader theory of identity, text, and meaning.

Komarraju, M., Karau, S. J., Schmeck, R. R., \& Avdic, A. (2011). The big five personality traits, learning styles, and academic achievement. Personality and Individual Differences, 51(4), 472-477.

Lai, Y.-S., Tsai, H.-H., \& Yu, P.-T. (2011). Integrating annotations into a dual-slide powerpoint presentation for classroom learning. Journal of Educational Technology \& Society, 14(2), 43-57. 
Lamb, T. (2007). Note together: a collaborative annotation system for the world-wide web. (Master's thesis, Batchelor dissertation, University of Bath.).

Lintean, M., Rus, V., \& Azevedo, R. (2012). Automatic detection of student mental models based on natural language student input during metacognitive skill training. International Journal of Artificial Intelligence in Education, 21(3), 169-190.

Mairesse, F., Walker, M. A., Mehl, M. R., \& Moore, R. K. (2007). Using linguistic cues for the automatic recognition of personality in conversation and text. Journal of artificial intelligence research, 457-500.

Marshall, C. C. (1998). Toward an ecology of hypertext annotation. In Proceedings of the ninth acm conference on hypertext and hypermedia: links, objects, time and spacestructure in hypermedia systems: links, objects, time and space-structure in hypermedia systems (pp. 40-49). ACM.

Marshall, C. C. (2009). Reading and writing the electronic book. Synthesis lectures on information concepts, retrieval, and services, 1(1), 1-185.

Mezghani, M., Zayani, C. A., Amous, I., \& Gargouri, F. (2012). A user profile modeling using social annotations: a survey. In Proceedings of the 21st international conference companion on world wide web (pp. 969-976). ACM.

Mostefai, B., Azouaou, F., \& Balla, A. (2012). Sqar: an annotation-based study process to enhance the learner's $p$ ersonal learning. In Towards learning and instruction in web 3.0 (pp. 17-33). Springer.

Naghsh, A. M. (2007). Supporting annotations in electronic paper-prototyping tools (Doctoral dissertation, Sheffield Hallam University).

Nunes, B. P., Kawase, R., Dietze, S., de Campos, G. H. B., \& Nejdl, W. (2012). Annotation tool for enhancing e-learning courses. In Advances in Web-Based Learning-ICWL 2012 (pp.51-60). Springer Berlin Heidelberg.

O'hara, K. \& Sellen, A. (1997). A comparison of reading paper and on-line documents. In Proceedings of the acm sigchi conference on human factors in computing systems (pp. 335-342). ACM.

Omheni, N., Mazhoud, O., Kalboussi, A., \& HadjKacem, A. (2014). Prediction of human personality traits from annotation activities. In Proceedings of the 10th international conference on web information systems and technologies (pp. 263-269). SciTePress.

Peabody, D. \& De Raad, B. (2002). The substantive nature of psycholexical personality factors: a comparison across languages. Journal of Personality and Social Psychology, 83(4), 983.

Pornsakulvanich, V., Dumrongsiri, N., Sajampun, P., Sornsri, S., John, S. P., Sriyabhand, T., Jiradilok, S. (2012). An analysis of personality traits and learning styles as predictors of academic performance. ABAC Journal, 32(3).

Porter-O'Donnell, C. (2004). Beyond the yellow highlighter: teaching annotation skills to improve reading comprehension. English Journal, 82-89.

Prasad, S., Singh, V. K., \& Sapre, A. (2010). Handwriting analysis based on segmentation method for prediction of human personality using support vector machine. International Journal of Computer Application (0975-8887), $12,8$.

Rahiman, A., Varghese, D., \& Kumar, M. (2013). Habit: handwritten analysis based individualistic traits prediction. International Journal of Image Processing (IJIP), $\pi(2), 209$. 
Sad, S. N., Goktas, O., \& Bayrak, I. (2014). A comparison of student views on web-based and face-to-face higher education. Turkish Online Journal of Distance Education, 15(2).

Sahinidis, A. G., Frangos, C. C., \& Fragkos, K. C. (2013). The relationship between personality type and academic performance. The case of greek university's students.

Seifert, K. \& Sutton, R. (2009). Educational psychology. (Chap. Student diversity, pp. 66-84).

Shahri, N., Javadi, M. J., \& Esmael, M. (2012). Reviewing relationship between personality types and learning styles on psychology students in bs degree at islamic azad university in tehran central branch.

Sumner, C., Byers, A., Boochever, R., \& Park, G. J. (2012). Predicting dark triad personality traits from twitter usage and a linguistic analysis of tweets. In Machine learning and applications (icm/a), 2012 11th international conference on (Vol. 2, pp. 386-393). IEEE.

Stanley, S. (2015). Attitude of Women Learners towards Distance Education: A Comparative Analysis. International Women Online Journal of Distance Education, 4(1).

Steimle, J., Brdiczka, O., \& Mühlhäuser, M. (2009). CoScribe: integrating paper and digital documents for collaborative knowledge work. Learning Technologies, IEEE Transactions on, 2(3), 174-188.

Wright, W. R. \& Chin, D. N. (2014). Personality profiling from text: introducing part-of-speech n-grams. In User modeling, adaptation, and personalization (pp. 243-253). Springer.

Xie, Q., \& Zhang, L. F. (2015). Demographic Factors, Personality, and Ability as Predictors of Learning Approaches. The Asia-Pacific Education Researcher, 24(4), 569-577.

Yueh, H.-P., Teng, Y.-T., Lin, W., Wang, Y.-C., \& Hu, C.-F. (2012). Web-based annotation learning system: construction and application. Creative Education, 3(08), 1297.

Zhou, M. (2015). Moderating effect of self-determination in the relationship between Big Five personality and academic performance. Personality and Individual Differences, 86, 385-389.

Zhou, C., \& Intaraprasert, C. (2015). Language learning strategies employed by Chinese English-major pre-service teachers in relation to gender and personality types. English Language Teaching, 8(1), 155.

Zywica, J. \& Gomez, K. (2008). Annotating to support learning in the content areas: teaching and learning science. Journal of Adolescent \& Adult Literacy, 52(2), 155-165. 